\title{
The influence of vehicle body roll angle on the motion stability and maneuverability of the vehicle
}

The article discusses the impact of design solutions of vehicle suspensions into angles of body roll. It was shown which type of suspensions is better from this point of view. There were examined the dependence of the suspensions parameters on the vehicle body roll angle. The influence of camber angle on the force transmitted to the tire contact with the road surface was analysed. The lateral forces were measured on the test stand. There was tested dependency of lateral forces from the sideslip angle for different angles of camber. Was analysed change of lateral forces generated by camber angle on the vehicle which was made on a scale $\sim 1: 5$ during tests carried out on the testing track. For this purpose, two tests have been selected: first one allowing the measurement in steady motion conditions, the second one with dynamic change of direction of vehicle motion. The graphs show the effect of camber angles on the controllability and stability of the vehicle motion.

Key words: stability of vehicle motion, suspensions, the interaction of the road and tires, the roll angle of vehicle body

\section{Introduction}

One of the tasks of the suspension of the vehicle is the appropriate wheel movement relative to the vehicle body. The controllability and stability of vehicle motion is influenced by: the stiffness and damping of suspension elements, suspension kinematics motion and changes the wheels angles. The solutions of design of suspensions affect the load and wheel inclination while performing various maneuvers by the vehicle. During analyzing the interaction of the wheel with the road surface, it can be determined which of the suspension construction is the most preferred for use in various types of vehicles. For this purpose, was conducted the study of dynamics of the physical model in a scale of 1:5, in which were assembled various types of suspension on the front and rear axles. This model fulfills criteria of similarity to medium truck $[1,2,11,14]$.

Tires parameters were determined during the tests on the test stand: stiffness in the longitudinal direction, transverse and radial and angular stiffness. In addition, were compared various parameters of the vehicle suspension: vertical stiffness and roll stiffness while maintaining the gross vehicle weight and moments of inertia. During the testing on the testing track were analyzed behavior of the vehicle during tests: the first one - driving on the circle track (quasi-static driving conditions) and the second one sudden changes of vehicle direction (dynamic driving conditions) [5, 6]. The study allowed to determine the effects of the suspension on the vehicle behavior [10].

\section{Influence of the kinds of suspension on the co-operation of the tire with the road surface}

The total force transmitted by the wheel on the road surface consists of the normal force and tangential forces (driving or braking, and lateral force). The maximum values of tangential forces are limited by the conditions of the adhesion [13]. The lateral force depends on the wheel angular stiffness and its inclination. Figure 1 shows a comparison of different kinds of vehicle suspensions during driving in a circular track.

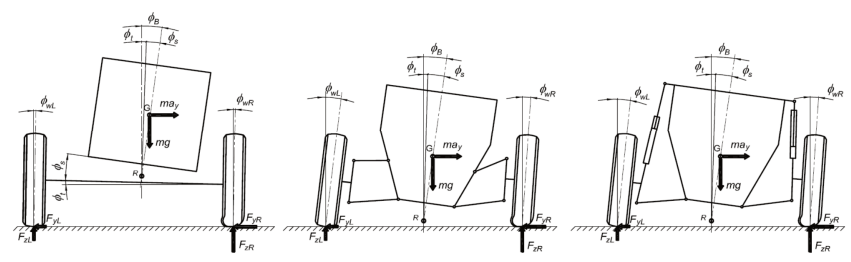

Fig. 1. Comparison of vehicles with different kinds of suspensions on a curvilinear track [own study]

In the case of dependent suspensions, camber angle is usually smaller than that of the car equipped with the double wishbone in suspensions. Suspensions equipped with McPherson's columns, generate slightly less camber angles. The vehicle body inclination angles depend on the kinematics and stiffness of the suspensions and are usually smaller for vehicles equipped with dependent suspensions. The use of anti-roll bar increases the angular stiffness of the vehicle. The anti-roll bar increases the angular stiffness of the suspension on the axis of the vehicle and protects it from excessive angles of body roll. During driving on a bend of the road, vehicle under the influence of the centrifugal forces incline towards the outer wheels. The anti-roll bar operates to reduce the differences of instantaneous loads on the elastic elements of suspensions of the wheels on one axle and reduces roll angles [13].

In vehicles equipped with suspension with rigid axles change camber depends on the susceptibility of the tires and the road surface irregularities. In the case of vehicles with independent suspensions angle of wheel inclination depends on the suspension geometry changes resulting from the vertical movement of wheel and the lateral inclination of the suspension. Figure 2 shows the camber angle according to the inclination of the vehicle body for different kinds of suspension: double wishbone, McPherson's column, and rigid axle [own study].

\subsection{The parameters of the vehicle suspensions}

For the analysis were chosen dependent suspension currently used in SUVs, vans and trucks, and an independent suspension with double wishbones of different lengths used in passenger cars and vans. The test method was used to 
determine the vertical and angular stiffness of the suspension and roll damping of suspension. The measurement results of suspensions stiffness are given in Table 1 .

Table 1. Comparison of parameters of the vehicle physical model equipped with various types of suspension [own research]

\begin{tabular}{|lr|c|c|c|c|}
\hline \multirow{2}{*}{ Parameter } & \multicolumn{2}{|c|}{ Dependent suspension } & \multicolumn{2}{c|}{ Independent suspension } \\
\cline { 3 - 6 } & & front axle & rear axle & front axle & rear axle \\
\hline Vertical stiffness & $\mathrm{K}_{\mathrm{s}}, \mathrm{N} / \mathrm{m}$ & 1910 & 1550 & 2980 & 5240 \\
\hline Vertical stiffness & $\mathrm{K}_{\mathrm{t}}, \mathrm{N} / \mathrm{m}$ & 1680 & 1680 & 1680 & 1680 \\
\hline Suspended mass & $\mathrm{m}_{\mathrm{s}}, \mathrm{kg}$ & 9,329 & 13,688 & 8,839 & 13,818 \\
\hline Unsuspended mass & $\mathrm{m}_{\mathrm{us}}, \mathrm{kg}$ & 1,667 & 1,648 & 2,662 & 2,783 \\
\hline
\end{tabular}

The following figures show the impact of vehicle body inclination angle to the wheels camber angles for different types of suspension, taking into account the correction caused by the anti-roll bars.

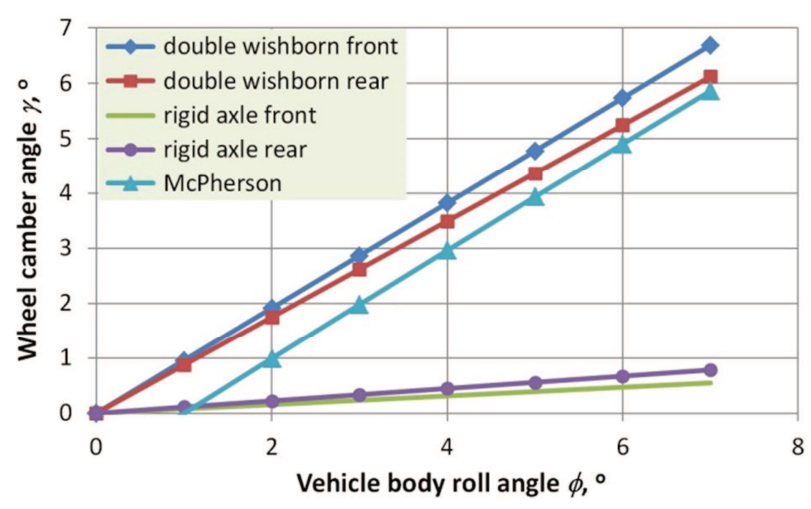

Fig. 2. The angle of wheel camber $\gamma$ as a function of vehicle body roll angle $\phi$ for different types of suspension (including the impact of tire deflection) [own research]
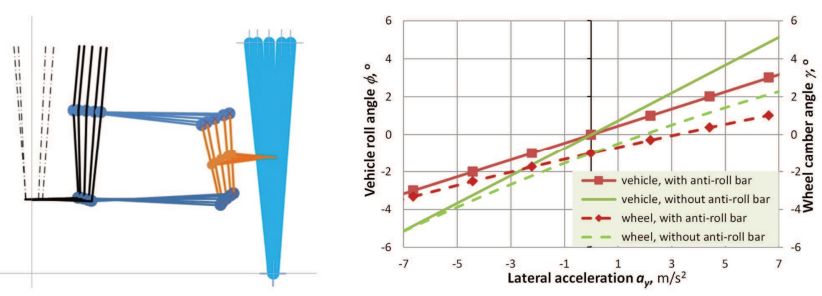

Fig. 3. The wheel camber changing $\gamma$ resulting from vehicle body roll angle $\phi$ equipped with suspension with double wishbone [own research]
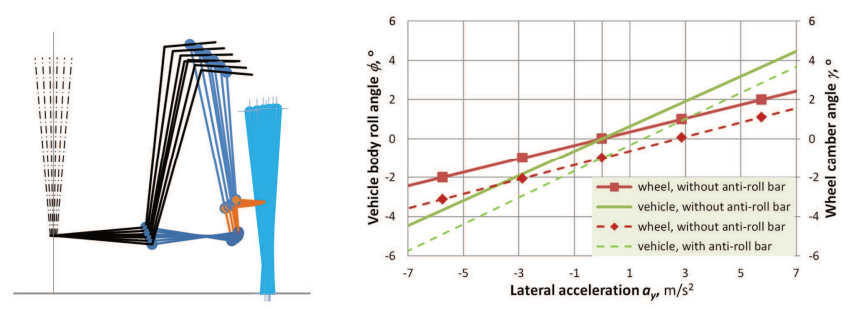

Fig. 4. The wheel camber changing $\gamma$ resulting from vehicle body roll angle $\phi$ equipped with McPherson suspension [own research]

\subsection{The parameters of the vehicle suspensions}

Figure 5 schematically shows the inclination of the car due to a lateral force.

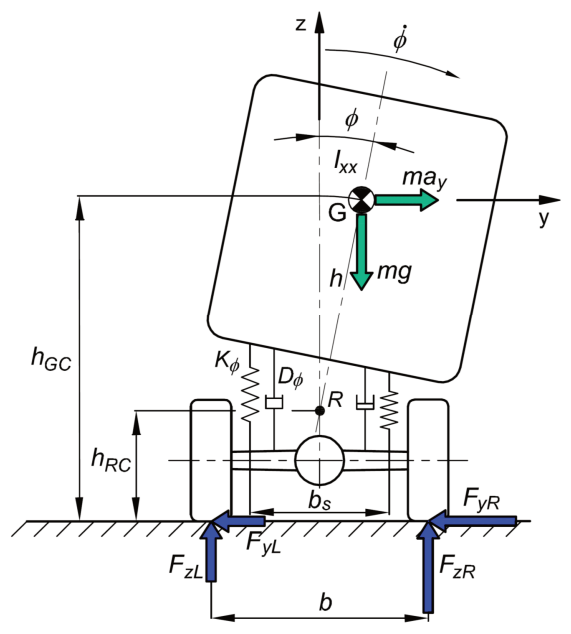

Fig. 5. The inclination of the vehicle caused by the lateral force [11]

The impact of tires deflection was omitted. Taking equation for the sum of lateral force and equation for the sum of moments about the roll centre it can be determined the impact of the location of centre of gravity on roll angle of the vehicle.

$$
\begin{aligned}
\mathrm{F}_{\mathrm{yf}(\mathrm{r})} & =\mathrm{m}_{\mathrm{s}} \cdot(\dot{\mathrm{V}} \cdot \sin \beta+\mathrm{V} \cdot \beta \cdot \cos \beta+\mathrm{V} \cdot \psi \cdot \cos \beta)= \\
& =\mathrm{m}_{\mathrm{s}} \cdot \mathrm{a}_{\mathrm{y}} \\
& \mathrm{M}_{\mathrm{RC}}=\mathrm{m}_{\mathrm{s}} \cdot \mathrm{g} \cdot\left(\mathrm{h}_{\mathrm{GC}}-\mathrm{h}_{\mathrm{RC}}\right) \cdot \sin \phi \\
& -\mathrm{D}_{\phi} \cdot \phi-\mathrm{K}_{\phi} \cdot \phi-\mathrm{K}_{\phi-\mathrm{ARB}} \cdot \phi+ \\
& +\mathrm{m}_{\mathrm{s}} \cdot(\dot{\mathrm{V}} \cdot \sin \beta+\mathrm{V} \cdot \beta \cdot \cos \beta+\mathrm{V} \cdot \psi \cdot \cos \beta) \cdot \\
& \left(\mathrm{h}_{\mathrm{GC}}-\mathrm{h}_{\mathrm{RC}}\right) \cdot \cos \phi=0
\end{aligned}
$$

For small roll angles $\phi$ it can be assumed that $\sin \phi \approx \phi$ and $\cos \phi \approx 1$, and that the lateral offset of centre of gravity, caused by inclination of the body, is so small that can be neglected. The equation (2) was used to determine how the lateral acceleration affects on the roll angle of the vehicle body (assuming that the lateral motion of the vehicle body is relatively slow).

$$
\begin{gathered}
\frac{\mathrm{M}_{\mathrm{RC}}}{\mathrm{b}_{\mathrm{s}}} \approx \frac{1}{\mathrm{~b}_{\mathrm{s}}} \cdot\left(\mathrm{m}_{\mathrm{s}} \cdot \mathrm{a}_{\mathrm{y}} \cdot\left(\mathrm{h}_{\mathrm{GC}}-\mathrm{h}_{\mathrm{RC}}\right)-\right. \\
\left.\mathrm{D}_{\phi} \cdot \phi-\mathrm{K}_{\phi} \cdot \phi-\mathrm{K}_{\phi_{-\mathrm{ARB}}} \cdot \phi\right)=0 \\
\mathrm{a}_{\mathrm{y}}=\frac{\mathrm{D}_{\phi} \cdot \phi+\left(\mathrm{K}_{\phi}+\mathrm{K}_{\phi_{-A R B}}\right) \cdot \phi}{\mathrm{m}_{\mathrm{s}} \cdot\left(\mathrm{h}_{\mathrm{GC}}-\mathrm{h}_{\mathrm{RC}}\right)}
\end{gathered}
$$

Hence, the simplification:

$$
\phi \approx\left(\mathrm{a}_{\mathrm{y}} \cdot\left(\mathrm{h}_{\mathrm{GC}}-\mathrm{h}_{\mathrm{RC}}\right) \cdot \mathrm{m}_{\mathrm{s}}-\mathrm{D}_{\phi} \cdot \phi\right) \cdot \frac{1}{\mathrm{~K}_{\phi}+\mathrm{K}_{\phi_{-} \mathrm{ARB}}}
$$

Analysing the equation (5) it can be stated that the roll angle of the vehicle body to a large extent, determined by the lateral acceleration, the distance from vehicle centre of gravity to the roll centre and ratio of the mass to the roll stiffness of the suspensions (including the influence of the anti-roll bar). 
Taking into account the deflection of tires, it will result in an increase in the roll angle of a few percent for trucks to several percent for passenger cars. Based on of research carried at the Laboratory of the Department of Internal Combustion Engines and Vehicles in University of BielskoBiala, was determined the maximum roll angle $\phi_{\mathrm{t}}$, resulting from the deflection of tires: for passenger cars $\sim 1.3^{\circ}$ and for trucks $\sim 0.7^{\circ}$.

Figures 6-8 shows the influence of the lateral acceleration, distance of centre of gravity from the roll centre and the suspension roll stiffness and damping.

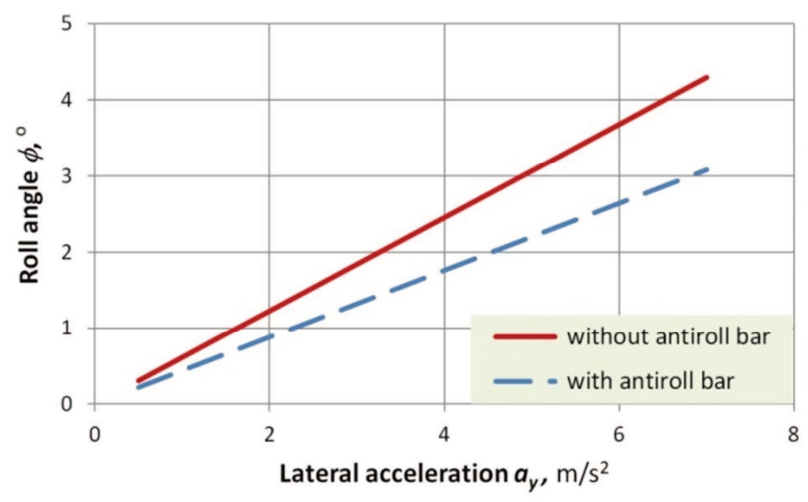

Fig. 6. The impact of lateral acceleration on the vehicle roll angle (for a full-size vehicle) [own research]

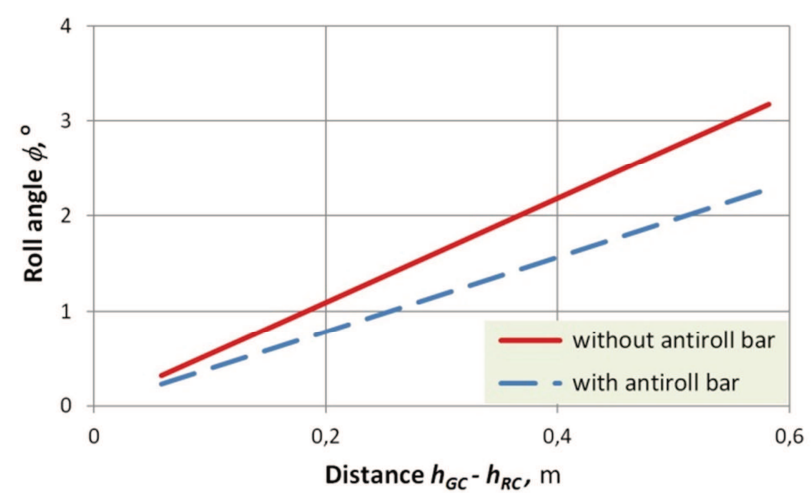

Fig. 7. Impact at vehicle roll angle of distance from centre of gravity to the roll centre (for a full-size vehicle) [own research]

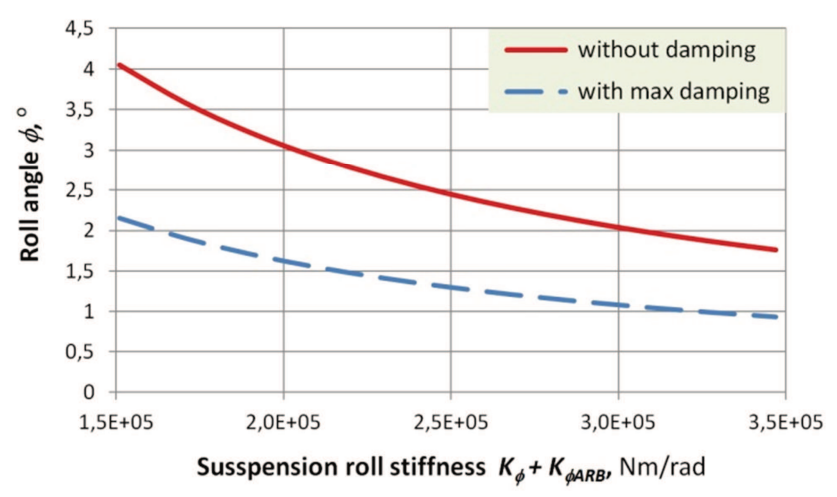

Fig. 8. The impact at vehicle roll angle of the roll stiffness of suspension (for a full-size vehicle) [own research]
On the vehicle roll angle also affects the product of roll rate and roll damping stiffness, in the dynamic states, it creates a temporary decrease in the roll angle. In Figure 8 is shown as dashed line, which represents the possible impact of roll rate and roll damping to temporarily change the roll angle (e.g during turning manoeuvre).

The maximum value of the roll angle for cars and trucks is about 4 to $7^{\circ}$, with the largest impact on the roll angle has lateral acceleration $\sim 56 \%$, slightly lower distance from centre of gravity to roll centre $\sim 46 \%$ and the minimum ratio of weight to suspension roll stiffness $\sim 8 \%$. Taking into account the deflection of the tire can change the roll angle to $\sim 4 \%$. Moment of inertia of the vehicle body will cause a delay of rolling. The use of anti-roll bars of the front and rear axles will cause a reduction in the roll angle of up to $30 \%$.

On the basis of this analysis, it can select the appropriate type of vehicle suspension with high and low located centre of gravity above ground. In the sports vehicle and passenger cars distance from the centre of gravity to the roll centre is relatively small and can be used suspension, in which the effect of vehicle body inclination on the roll angle is greater. In cars with a high located centre of gravity for example SUV and trucks should be used suspension, in which the inclination of the vehicle body has a little effect on the wheel camber angles.

\section{The impact of wheel camber angle on the transmission of forces on the tire contact with the road}

Changes in camber angles cause a change in footprint the tire contact with the road and affect on change of the value of lateral force transmitted to the road $[8,9]$. Because the side force is limited by the terms of adhesion, and depends on the wheel load, the cornering stiffness $K_{\alpha i}$ will not be constant and will vary.

Lateral force between wheel and ground depends on the sideslip angle $\alpha$ and camber angle $\gamma$ and is described by equation (6a) [4]. For larger sideslip angles R. Jazar [7] recommends the use of a simplified equation (6b), taking into account the non-linear curve of the lateral force:

$$
\mathrm{F}_{\mathrm{yi}}=-\mathrm{K}_{\alpha \mathrm{i}} \cdot \alpha_{\mathrm{i}}+\mathrm{K}_{\gamma \mathrm{i}} \cdot \gamma_{\mathrm{i}}
$$

where $\mathrm{i}-$ an index indicating the $\mathrm{i}$-th wheel

$$
\mathrm{F}_{\mathrm{y}}=-\mathrm{K}_{\alpha} \cdot \alpha \cdot\left(1-\frac{1}{3}\left|\frac{\mathrm{K}_{\alpha} \cdot \alpha}{\mathrm{F}_{\mathrm{yM}}}\right|+\frac{1}{27}\left(\frac{\mathrm{K}_{\alpha} \cdot \alpha}{\mathrm{F}_{\mathrm{yM}}}\right)^{2}\right)+\mathrm{K}_{\gamma} \cdot \gamma
$$

The wheel camber angle will cause a change of the tire footprint on the roadway and thus the formation of the lateral force component depends on the camber angle $\gamma$. In addition, will appear some point shift reaction force $F_{z}$ from the wheel axis. In Figure 10b was shown the impact of wheel camber angle on the tire footprint shape on the roadway.

When vehicle is driving with lateral acceleration under steady state conditions (e.g. during cornering), on the vehicle operates the centrifugal force, which can be determined 
from equation $\mathrm{F}_{\mathrm{y}}=\mathrm{m} \cdot \mathrm{a}_{\mathrm{y}}$. This lateral force can be decomposed into components acting on the front and rear axles.

$$
\mathrm{F}_{\mathrm{y}}=\mathrm{F}_{\mathrm{yf}}+\mathrm{F}_{\mathrm{yr}}
$$

The forces acting on the front and rear axles, for small sideslip angles of wheels, can also be determined from equation:

$$
\begin{gathered}
\mathrm{F}_{\mathrm{yf}}=\mathrm{F}_{\mathrm{y}} \cdot \frac{\mathrm{a}_{2}}{\mathrm{~L}_{\mathrm{w}}} \\
\mathrm{F}_{\mathrm{yr}}=\mathrm{F}_{\mathrm{y}} \cdot \frac{\mathrm{a}_{1}}{\mathrm{~L}_{\mathrm{w}}}
\end{gathered}
$$

Based on the analysis equation (6b) can be seen that when the vehicle is moving on the curvilinear track under steady state conditions (fixed side force), the increase of camber angle, will affect the decrease value of lateral force and at the same values of this force the value of wheel sideslip angle $\alpha$ will be increased.

Sideslip angles of the wheels can be determined from equations (9a) and (9b) [3].

$$
\begin{gathered}
\alpha_{f}=\frac{W_{f}}{g \cdot K_{\alpha f}} \cdot a_{y}-\frac{K_{\gamma f}}{K_{\alpha f}} \cdot \gamma_{f} \\
\alpha_{r}=\frac{W_{r}}{g \cdot K_{\alpha r}} \cdot a_{y}-\frac{K_{\gamma r}}{K_{\alpha r}} \cdot \gamma_{r}
\end{gathered}
$$

They were defined functional dependencies of wheels camber angle as a function of vehicle body roll angle and a vehicle body roll as a function of lateral acceleration, based on the results of research and analysis for various types of suspensions. The values of tires cornering stiffness and camber stiffness were determined from measurements on the test stand [10].

\section{The impact of wheel camber angle on the transmission of forces on the tire contact with the road}

Lateral force measurements were conducted on a test stand [10] using the tire used in physical model for various wheel sideslip angles $\alpha$ at fixed value of camber angles $\gamma$ (in the range of 0 to $10 \mathrm{deg}$ ).
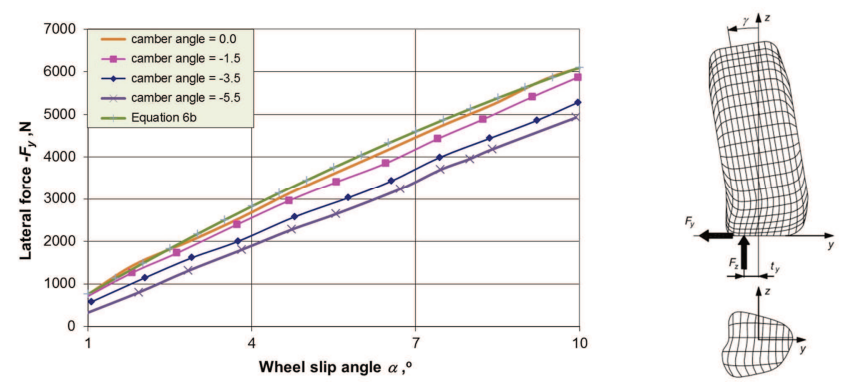

Fig. 9. a) Lateral force on the wheel contact with the road Fy at various wheel camber angles $\gamma$, depending on the wheel sideslip angles $\alpha$ (for a full-dimensional vehicle) [own research], b) The lateral and vertical force and a footprint of the contact on the road surface caused by wheel camber angle
Figure 9a shows a comparison of the lateral force determined from the equation (6b), and obtained from measurements on the test stand [10]. The lateral force $-\mathrm{F}_{\mathrm{y}} \mathrm{de}-$ creases with increasing camber $\gamma$ from a few to several percent, proportional to the wheels sideslip angle.

The values of angular stiffness of tire and camber stiffness were determined on the basis of measurements which were made on the test stand. The values shown in table 2 were obtained from measurements and were multiplied by scale factors of similarity (for full-dimensional vehicle).

The impact of the vehicle body roll angle on stability and steerability of the vehicle were verified during the tests of physical vehicle model at scale $\sim 1: 5$, conducted on the test track.

Table 2. The stiffness of tire for full-dimensional vehicle determined on the basis of the tire of the physical model [own research]

\begin{tabular}{|l|c|c|c|}
\hline \multicolumn{2}{|l|}{ Parameter } & Front axle & Rear axle \\
\hline Vertical stiffness & $K_{z}, \mathrm{~N} / \mathrm{mm}$ & 923 & 1151 \\
\hline Lateral stiffness & $K_{y}, \mathrm{~N} / \mathrm{mm}$ & 70 & 82 \\
\hline Cornering stiffness & $K_{\alpha}, \mathrm{N} / \mathrm{rad}$ & 68800 & 76000 \\
\hline Camber stiffness & $K_{\gamma} \mathrm{N} / \mathrm{rad}$ & 3305 & 3569 \\
\hline
\end{tabular}

The influence of the vehicle body roll angle on the stability and steerability of the vehicle were verified during the tests of the vehicle model in a scale performed on the test track.

\section{Analysis of influence of the camber angle on the dynamics of vehicle motion based on tests of the physical model}

\subsection{Measurements of stability and steerability \\ performed with using the vehicle model}

During measurements of stability and steerability of vehicles are used standardized research tests: driving in a circular path at a steady-state condition (ISO 14792) [5], step steering input (ISO 14793) [6], dynamic stability of the vehicle motion (AVTP 03-160 - test of avoid an obstacle on the road) and other [12]. For study were chosen two tests based on the driving on a circular path in steady-state conditions and test of a response on sudden change of the steering wheel rotation.

For testing was used a physical model of the vehicle made on a scale $\sim 1: 5$, which fulfilled criteria of similarity to the commercial vehicle (LCV) [11,14]. Using the theory of similarity, were chosen the trajectory and the parameters of motion to the scale of the vehicle. The runs of the tests has been programmed in the controller of model.

On the vehicle model was mounted measuring equipment VBOX 3i Racelogic based on GPS technology, allowing for registration of the trajectory and parameters of the motion: velocity, longitudinal and lateral acceleration, angular velocity of vehicle motion about axis passing through centre of gravity and roll angle of the vehicle [15]. Figure 10 shows a model prepared for the tests. During the tests on the model were assembled various types of suspension and additionally also were mounted anti-roll bars on the front and rear axles. 


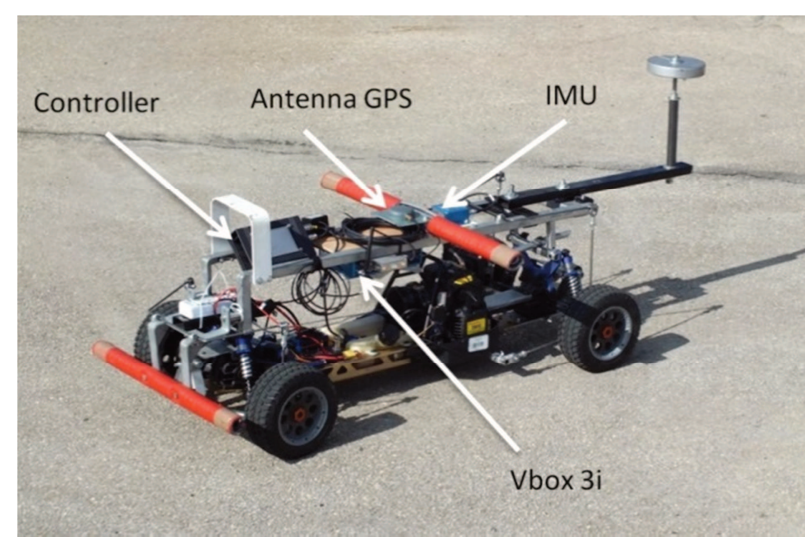

Fig. 10. The physical model of the vehicle on a scale $\sim 1: 5$ with mounted measuring apparatus

\subsection{Analysis of influence of camber angle on the vehicle stability and steerability}

During the tests, after the start the vehicle was moving straight for about 3 seconds to achieve the required speed and then performed a manoeuvre of turn right and for about four seconds was moving along a circular path, would then return to the straight track and stop. Steering angle of wheels, velocity and duration of individual manoeuvres were programmed and performed by the controller. This test allows for conducting research under conditions of dynamic changes of motion direction and during the driving on a circular path in steady-state conditions.

Figure 11 shows the run of the velocity during transient and steady-state motion.

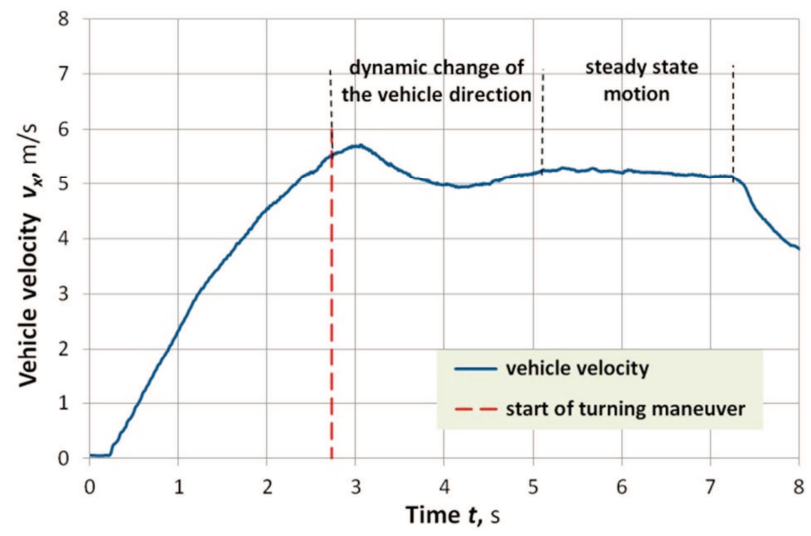

Fig. 11. The run of vehicle motion velocity during the test. [own research]

The following figure shows the vehicle body roll angle (Fig. 12) depending on mounted suspension in the vehicle. The red curve shows the vehicle body roll angle with mounted dependent suspension at front and rear axles. The curve of blue colour shows the vehicle body roll angle with independent suspension for both axles and the green one shows the vehicle with independent suspension (two wishbones) mounted on the front axle and with the rear rigid axle. The body roll angles are greatest in a vehicle with independent suspension $\sim 13^{\circ}$ and the smallest in the vehicle equipped with dependent suspension $\sim 7^{\circ}$. In the first case, with the independent suspension on both axles, the roll angle in the initial phase of the turning reached to $13^{\circ}$ and then decreased up to $6^{\circ}$. In the case of independent suspen- sion on the front axle and dependent on the rear one (green curve) roll angle reached up to $9^{\circ}$ in the initial phase of the manoeuvre, order then to decrease to $4^{\circ}$. While a vehicle was equipped with a suspension with rigid axles (red curve) the roll angles were of $\sim 7^{\circ}$ to fall in the final phase to $2.5^{\circ}$.

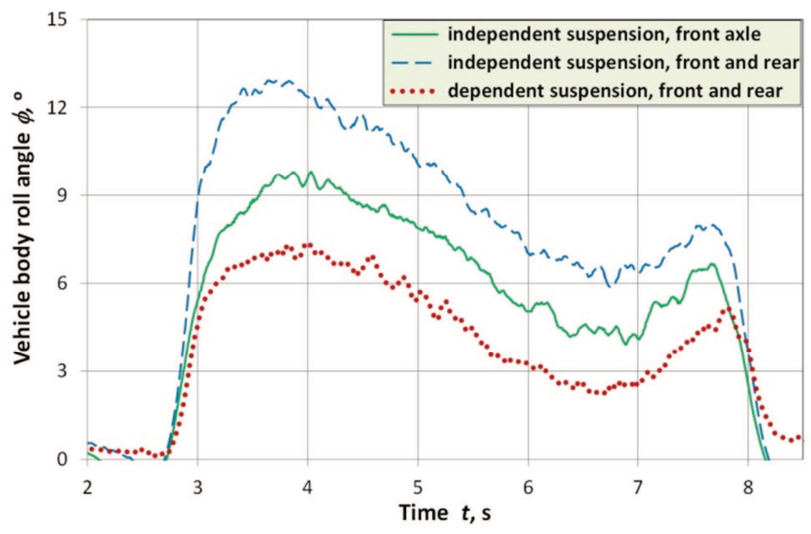

Fig. 12. The run of the vehicle body roll angle during the test. [own research]

Figure 13 shows influence of the camber angle on the side slip angle of wheels.

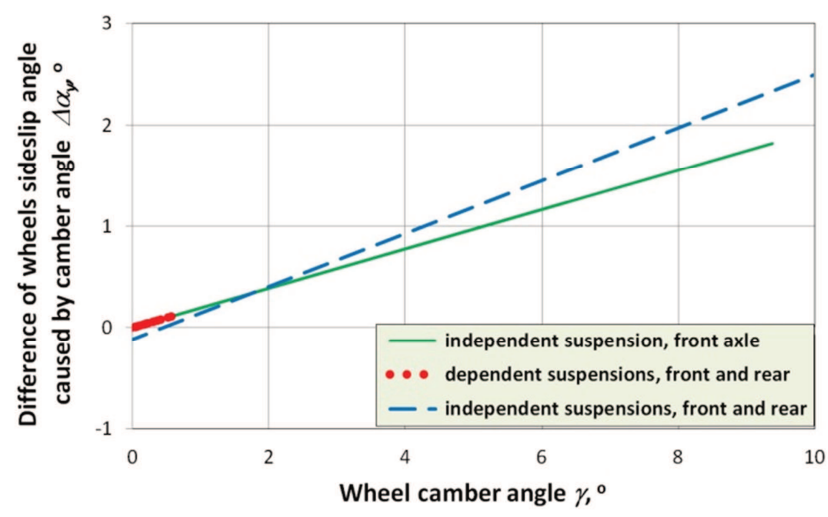

Fig. 13. The influence of camber angle $\gamma$ on the difference of wheels side slip angle $-\Delta \alpha$ [own research]

Camber angles have an influence on the side slip angles, and their change does not exceed $\sim 3^{\circ}$ for a vehicle equipped with an independent suspension on both axles, $\sim 1.75^{\circ}$ for the vehicle with independent suspension on the front axle and dependent on the rear one, and $\sim 0.3^{\circ}$ for a vehicle equipped with dependent suspension on both axles. Figure 14 shows difference of side slip angles of wheels of the front and rear axle for different suspension types mounted on the vehicle. The vehicle equipped with different suspension on the front and the rear axle had oversteer characteristics. The vehicle had understeering characteristics for other combinations of the suspensions.

Vehicle with different suspension of front and rear axles in the initial part of the test (dynamic change of the direction of motion) clearly tightened the turn. A vehicle equipped with independent suspension on both axles in the initial part of the test increased the radius of curvature of the track. A vehicle equipped with a dependent suspension to a much lesser extent increased the radius of the track. In 
the part of the test, while the vehicle was moving in steadystate condition, radii of curvature of the tracks were very similar.

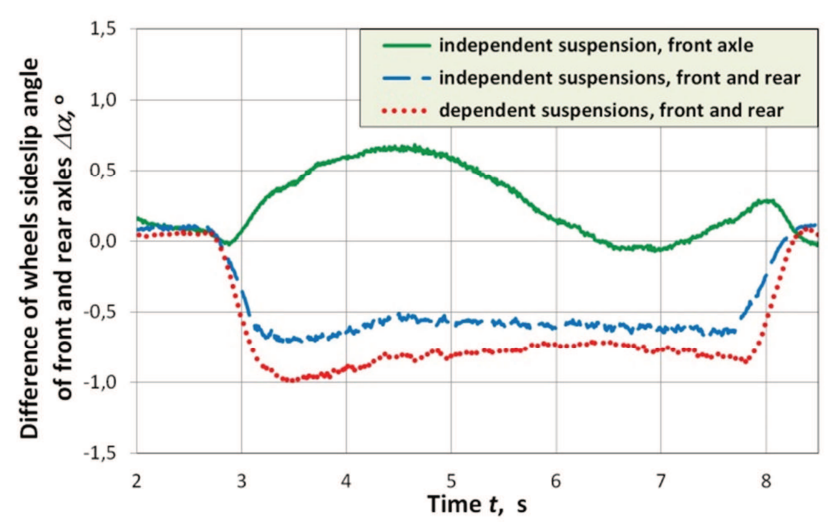

Fig. 14. The influence of roll angle $\phi$ on the difference of wheels side slip angle of front and rear axles. [own research]

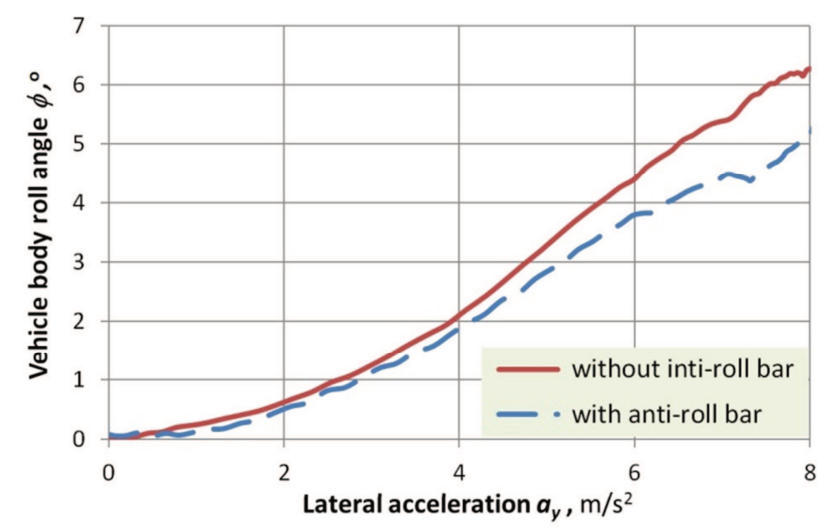

Fig. 15. The influence of anti-roll bars on the vehicle body roll angle. [own research]

The application of anti-roll bars in the suspensions of vehicles reduces the roll angles (Fig. 15). During the tests of the model has been observed reducing of the vehicle roll angle more than 1 degree (about 15\%). This was due to increase reactions forces on the unloading wheels (at large roll angles, even up to $40 \%$ ) and in result the improvement of lateral stability. The use of anti-roll bars allowed the transfer the larger driving forces during the intense turn manoeuvres (even at high lateral accelerations). During the road tests was observed a slight decrease of the trajectory radius of the vehicle motion, resulting from better load distribution on the sides of the vehicle.

\section{Summary and conclusions}

In vehicles equipped with suspension with rigid axles the change of the camber angle results from the compliance of the tires and the road surface irregularities. In the case of vehicles with independent suspension the camber angle also depends on the suspension geometry changes resulting from its the vertical movement and from the vehicle body roll angle. Changes of camber angles will change the contact patch the tire with the road and affect to change of the size of lateral force transmitted on the road surface.

On basis of conducted tests and studies it can be concluded about choosing the right type of suspension for vehicles with high and low centre of gravity position. In the sport vehicles and classical passenger cars the distance between the roll axis and the centre of gravity is relatively small and can be used suspensions, in which the influence of vehicle body roll angle on the camber angle is greater. In cars with a high position of gravity centre, for example multipurpose vehicle (SUV - sport utility vehicle) and trucks (CV - commercial vehicle) should be applied suspension, in which the vehicle body roll angle has little effect on camber angles.

Larger camber angles effect on increasing the side slip angles. The application of different suspensions can cause variation of side slip angles difference of front and rear axle and thereby affect on understeer and oversteer of the vehicle. This is particularly apparent when dynamically changes direction of the vehicle motion. During the driving in a circular path at steady-state condition influence of the applied suspension is much less felt. The use of independent suspensions on the front and rear axle in trucks results in a significant increase in vehicle roll angle, which increases the risk of vehicle rollover and deteriorates the properties of vehicle motion, both in quasi-static and dynamic conditions.

The use of anti-roll bars on the front and rear axles results in decrease the vehicle roll angles and thereby improving cooperation the wheel with the road surface, and increasing steerability and stability of the vehicle.

\section{Nomenclature}

$\alpha \quad$ sideslip angle of wheel, ${ }^{\circ}, \mathrm{rad}$

$\Delta \alpha \quad$ difference of wheels sideslip angle of front and rear axles, ${ }^{\circ}$, rad

$\Delta \alpha_{y} \quad$ difference of wheels sideslip angle caused by camber angle, ${ }^{\circ}$, rad

$\beta \quad$ vehicle slip angle, ${ }^{\circ}, \mathrm{rad}$

$\gamma \quad$ camber angle of wheel, ${ }^{\circ}, \mathrm{rad}$

$\phi \quad$ roll angle of the vehicle body, ${ }^{\circ}, \mathrm{rad}$

$\phi_{s} \quad$ roll angle of the sprung mass, ${ }^{\circ}, \mathrm{rad}$

$\phi_{t} \quad$ roll angle of the vehicle body caused by tire, ${ }^{\circ}$, rad

$\dot{\phi}$. $\quad$ roll rate of the vehicle, $1 / \mathrm{s}$ $\dot{\psi}$. $\quad$ yaw rate of the vehicle, $1 / \mathrm{s}$

$a_{1}, a_{2}$ distance of the centre of gravity from the front/rear axle, $\mathrm{m}$

$a_{x} \quad$ longitudinal acceleration $\left(a_{x}=\dot{V}\right), \mathrm{m} / \mathrm{s}^{2}$

$a_{y} \quad$ lateral acceleration, $\mathrm{m} / \mathrm{s}^{2}$

$b \quad$ wheel tread, $m$

$b_{s} \quad$ lateral separation between the springs, $\mathrm{m}$

$C_{\gamma} \quad$ tire camber stiffness, $\mathrm{N} / \mathrm{rad}$

$C_{\alpha} \quad$ tire cornering stiffness, $\mathrm{N} / \mathrm{rad}$

$C_{z} \quad$ tire vertical stiffness, $\mathrm{N} / \mathrm{m}$

$C_{y} \quad$ tire lateral stiffness, $\mathrm{N} / \mathrm{m}$ 
$D_{\phi} \quad$ roll damping of suspension, $\mathrm{Nms} / \mathrm{rad}$

$F_{S L(S R)} \quad$ vertical force acting as a result of the deflection of the left (right) spring, $\mathrm{N}$

$F_{y f}, F_{y r}$ lateral force acting on the front/rear wheel, N

$F_{y L(R)} \quad$ lateral force acting on the left wheel (right), N

$F_{y M} \quad$ maximum value of the lateral force, $\mathrm{N}$

$F_{z L(z R)} \quad$ vertical force acting on the left wheel (right), N

$g \quad$ gravity acceleration, $\mathrm{m} / \mathrm{s}^{2}$

$h$ distance between the center of gravity and the roll center, $\mathrm{m}$

$h_{G C} \quad$ height of the center of gravity above the ground, $m$

$h_{R C} \quad$ the height of the roll center above the ground, $\mathrm{m}$

$i \quad$ an index

$K_{\phi} \quad$ the roll stiffness of suspension, $\mathrm{Nm} / \mathrm{rad}$
$K_{\phi_{-} A R B}$ additional roll stiffness suspension caused by a anti-roll bar, $\mathrm{Nm} / \mathrm{rad}$

$k_{s} \quad$ suspension stiffness, $\mathrm{N} / \mathrm{m}$

$k_{t} \quad$ vertical tire stiffness, $\mathrm{N} / \mathrm{m}$

$k_{\alpha} \quad$ cornering tire stiffness, $\mathrm{N} / \mathrm{rad}$

$L_{w} \quad$ wheelbase $\left(L_{w}=a_{1}+a_{2}\right), \mathrm{m}$

$M_{R C} \quad$ sum of moments about the roll centre, $\mathrm{Nm}$

$m \quad$ mass of vehicle $\left(m_{u s}+m_{s}\right), \mathrm{kg}$

$m_{s} \quad$ „sprung” mass of vehicle, $\mathrm{kg}$

$m_{u s} \quad$,unsprung” mass of vehicle, $\mathrm{kg}$

$R \quad$ roll centre point,

$r \quad$ the radius of the track, $m$

$R_{y}, R_{z} \quad$ the reactions operating in the roll centre, $\mathrm{N}$

$V$ the speed of a moving vehicle, $\mathrm{m} / \mathrm{s}$

$W_{f}, W_{r}$ load of front/rear axle, $\mathrm{N}$

\section{Bibliography}

[1] BAKER, W.E., EESTINE, P.S., DODGE, F.T. Similarity methods in engineering dynamics. Theory and practice of scale modeling. 9th ed. New Jersey: Spartan Books. 1978, 83-142.

[2] BUCKINGHAM, E. On physically similar systems: Illustration of the use of dimensional equations. Physics Review. 1914, 4, 345-376.

[3] GILLESPIE, T.D. Fundamentals of vehicle dynamics. 1st ed. Warrendale: SAE. 1992, 198-219.

[4] GUZEK, M., LOZIA, Z., REŃSKI, A. The influence of angular stiffness of suspension on the lateral stability of the two-axle vehicle on the example of light comercial vehicle. Zeszyty Naukowe Instytutu Pojazdów. Politechnika Warszawska. 1998, 3, 17-29.

[5] ISO 14792:2003. Heavy Commercial vehicles and Articulated Buses. Steady state circular test.

[6] ISO 4138:2012. Passenger cars. Steady-state circular driving behavior. Open-loop test methods.

[7] JAZAR, R.N. Vehicle dynamics. Theory and application. 2nd ed. New York: Springer. 2008, 135-151.

[8] LOZIA, Z. A two-dimensional model of the interaction between pneumatic tyre and an uneven road surface. Vehicle System Dynamics: International Journal of Vehicle Mechanics and Mobility. 1988, 17(1), 227-238.

Krzysztof Parczewski, DSc., DEng. - Faculty of Mechanical Engineering and Computer Science at University of Bielsko-Biała.

e-mail: kparczewski@hth.bielsko.pl

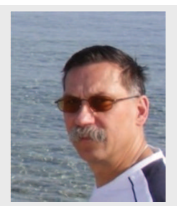

[9] LUTY, W., PROCHOWSKI, L. The possibility of transferring lateral forces by the tires of a truck on a bend of the road. Zeszyty Naukowe Instytutu Pojazdów. Politechnika Warszawska. 2004, 3(54), 61-70.

[10] PARCZEWSKI, K., WNĘK, H. The tyre characteristics of physical models used to investigate vehicles lateral stability. Proceedings of the Institution of Mechanical Engineers, Part D: Journal of Automobile Engineering. 2015, 229(10), 1419-1426.

[11] PARCZEWSKI, K, WNĘK, H. Using mobile scaled vehicle to investigate the truck lateral stability. Eksploatacja $i$ Niezawodnosc Maintenance and Reliability. 2013, 15(4), 415421.

[12] PIENIĄŻEK, W. Selected issues of research on the vehicle stability and steerability. Zeszyty Naukowe Instytutu Pojazdów. Politechnika Warszawska. 2010, 3(79), 29-43.

[13] REŃSKI, A. Vehicles active safety. The suspension, steering and braking systems. 1st ed. Warszawa. Oficyna Wydawnicza Politechniki Warszawskiej. 2011, 1-36.

[14] ROMANISZYN, K.M. Mobilne modele samochodów do badań stateczności. Logistyka. 2012, 3, 1927-1934.

[15] ROMANISZYN, K.M. Comparison of dynamic parameters of a special-purpose vehicle with different centre of gravity locations. Zeszyty Naukowe Instytutu Pojazdów. Politechnika Warszawska. 2010, 1(77), 291-299.

Henryk Wnęk, DEng. - Faculty of Mechanical Engineering and Computer Science at University of Bielsko-Biała.

e-mail:hwnek@ath.bielsko.pl

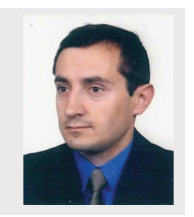

